\section{The usefulness of c-Kit in the immunohistochemical assessment of melanocytic lesions}

\author{
L. Pilloni, ${ }^{1}$ P. Bianco, ${ }^{1}$ E. Difelice, ${ }^{1}$ \\ S. Cabras, ${ }^{2}$ M.E. Castellanos, ${ }^{3}$ L. Atzori, ${ }^{4}$ \\ C. Ferreli, ${ }^{4}$ P. Mulas, ${ }^{5}$ S. Nemolato, \\ G. Faa'
}

'Department of Cytomorphology, Division of Pathology, University of Cagliari, Italy;

2Department of Mathematics and

Informatics, University of Cagliari, Italy;

${ }^{3}$ Department of statistics and O.R.,

University Rey Juan Carlos, Madrid,

Spain;

${ }^{4}$ Department of Dermatology, University

of Cagliari, Italy;

${ }^{5} \mathrm{UO}$ of Dermatology, Hospital Businco,

Cagliari, Italy

\section{Abstract}

C-Kit (CD117), the receptor for the stem cell factor, a growth factor for melanocyte migration and proliferation, has shown differential immunostaining in various benign and malignant melanocytic lesions. The purpose of this study is to compare c-Kit immunostaining in benign nevi and in primary and metastatic malignant melanomas, to determine whether c-Kit can aid in the differential diagnosis of these lesions. c-Kit immunostaining was performed in 60 cases of pigmented lesions, including 39 benign nevi ( 5 blue nevi, 5 intradermal nevi, 3 junctional nevi, 15 cases of primary compound nevus, 11 cases of Spitz nevus), 18 cases of primary malignant melanoma and 3 cases of metastatic melanoma. The vast majority of nevi and melanomas examined in this study were positive for c-Kit, with minimal differences between benign and malignant lesions. C-Kit cytoplasmatic immunoreactivity in the intraepidermal proliferating nevus cells, was detected in benign pigmented lesions as well as in malignant melanoma, increasing with the age of patients $(\mathrm{P}=0.007)$ in both groups. The patient's age at presentation appeared to be the variable able to cluster benign and malignant pigmented lesions. The percentage of c-Kit positive intraepidermal nevus cells was better associated with age despite other variables $(\mathrm{P}=0.014)$. The intensity and percentage of $\mathrm{c}$-Kit positivity in the proliferating nevus cells in the dermis was significantly increased in malignant melanocytic lesions $(\mathrm{P}=0.015$ and $\mathrm{P}=0.008$ ) compared to benign lesions (compound melanocytic nevi, Spitz nevi, intradermal nevi, blue nevi). Immunostaning for c-Kit in metastatic melanomas was negative. Interestingly in two cases of melanoma occurring on a pre-existent nevus, the melanoma tumor cells showed strong cytoplasmatic and membranous positivity for c-kit, in contrast with the absence of any immunoreactivity in pre-existent intradermal nevus cells. C-Kit does not appear to be a strong immunohistochemical marker for distinguishing melanoma from melanocytic nevi, if we consider c-Kit expression in intraepidermal proliferating cells. The c-Kit expression in proliferating melanocytes in the dermis could help in the differential diagnosis between a superficial spreading melanoma (with dermis invasion) and a compound nevus or an intradermal nevus. Finally, c-Kit could be a good diagnostic tool for distinguishing benign compound nevi from malignant melanocytic lesions with dermis invasion and to differentiate metastatic melanoma from primary melanoma.

\section{Introduction}

C-Kit is a transmembrane receptor tyrosine kinase that binds stem cell factor (SCF) ${ }^{1-3} \mathrm{C}$ Kit is encoded by the kit proto-oncogene, localized to human chromosome 4 and to mouse chromosome $5 ., 5$ The c-Kit/SCF interaction is critical for the survival and development of stem cells involved in hematopoiesis, ${ }^{6}$ in pancreas development ${ }^{7}$ and in melanogenesis. ${ }^{8}$ The c-Kit gene product is expressed in several normal cell types including mast cells, the interstizial cells of Cajal and the melanocytes and epithelial cells of the breast. ${ }^{9}$ Alterations in c-Kit expression are seen in a variety of neoplasms including mastocitosis, gastrointestinal cell tumors (GISTs) and germ cell tumors. ${ }^{10}$ After binding to the stem cell factor, c-Kit begins a signal cascade that contributes to the growth and differentiation of multiple hematopoietic lineages. ${ }^{11}$ Previous studies have shown that c-Kit is expressed in junctional components of benign compound nevi ${ }^{12}$ and it is frequently positive in superficial spreading melanoma (early stage); ${ }^{13}$ this positivity is lost in the vertical growth phase of invasive melanoma. ${ }^{14-17}$ More interestingly, a loss of cKit immunostaining from primary malignant melanoma to metastatic melanoma in the same patients has been reported. ${ }^{18}$ Malignant transformation of melanocytes is associated with changes in the expression of c-Kit. Several studies have demonstrated that the progression of human melanoma is associated with the loss of expression of c-Kit. ${ }^{8,14,15}$ These studies revealed that expression of the tyrosine kinase receptor encoded by the c-Kit
Correspondence: Luca Pilloni, Department of Cytomorphology, Division of Pathology, University of Cagliari, via 0spedale, 54, 09124 Cagliari, Italy.

Tel. +39.070 .6092424 . Fax: +39.070 .6092370 .

E-mail: lucpilloni@tiscali.it

Key words: c-kit, melanoma, nevi.

Received for publication: 23 December 2011. Accepted for publication: 6 May 2011.

This work is licensed under a Creative Commons Attribution NonCommercial 3.0 License (CC BYNC 3.0).

(C) Copyright L. Pilloni et al., 2011

Licensee PAGEPress, Italy

European Journal of Histochemistry 2011; 55:e20 doi:10.4081/ejh.2011.e20

proto-oncogene gradually declines during growth and invasion of human melanoma. ${ }^{8,14-16}$ The explanation for the loss of $c$-Kit expression in melanoma progression has still not been fully explained. Since SCF plays a crucial role in melanocyte proliferation, there is an interest in the diagnostic or treatment potentials of c-Kit in melanocytic lesions, especially in melanoma. Given the heterogeneous appearance of malignant melanoma, diagnostic difficulties $^{19}$ and poor inter-observer reproducibility, this study was designed to assess whether the expression of c-Kit identifies differences in melanocytic lesions, considering benign nevi, primary melanoma and metastatic melanoma.

\section{Materials and Methods}

A retrospective study was initiated to review the medical records of all patients with a diagnosis of benign nevus and malignant melanoma between 2008 and 2009 at the Anatomy Pathology Division, University of Cagliari, Italy. Through a careful clinicalpathological correlation, we identified 60 cases of pigmented lesions grouped into 39 cases of benign nevus ( 5 blue nevi, 5 intradermal nevi, 3 junctional nevi, 15 cases of primary compound nevus, 11 cases of Spitz nevus), 18 cases of primary melanoma and 3 cases of metastatic melanoma. Five micron paraffin sections from benign and malignant melanocytic lesions were immunostained for CD117, c-Kit, (cod,A4502 polyclonal rabbit anti-Human CD117, c-Kit, DAKO, Carpinteria, CA, USA), diluted 1:200. The incubation time of the primary antibody was $30 \mathrm{~min}$. Heat induced antigen retrieval was adopted (20 min at $98^{\circ}$ in Tris/edta pH9). We used the Dako cytomation LSAB2 system-HRP (DAKO) that is 
based on a modified labelled avidin-biotin (LAB) technique in which a biotinylated secondary antibody forms a complex with peroxidase-coniugated strepavidin molecules. Endogenous peroxidase activity was quenched by incubating $(5 \mathrm{~min})$ specimens with $3 \%$ hydrogen peroxide. The staining was completed after incubation (10 min) with 3 -amino9.ethyl carbazole (AEC) substrate chromogen, which resulted in a red-colored precipitate at the antigen site. Slides were reviewed by two pathologists who were not aware of the clinical data, and evaluated it for both tumor cell percentage and intensity of immunoreactivity. The percentage of positive cells was recorded as $0=$ negative; $1=<5 \%$ of cells staining; $2=5$ $50 \%$ of cells staining; $3=51-95 \%$ of cells staining; and $4=>95 \%$ of cells staining. ${ }^{20}$ Intensity was scored as 0 (negative), 1+ (weak), 2+ (moderate), and 3+ (strong), and evaluated by comparing contiguous epidermal melanocytes and interstitial mast cells (considering moderately positive contiguous melanocytes $(2+)$ and intensely positive (3+) dermal mast cells). The product of the percentage and the intensity score was used as the final measure of the staining. Differences in c-Kit immunoreactivity in the top and in the bottom of lesions were as well evaluated. Further variables considered in the present study were: maximal dimensions of lesions, age and sex of patients.

\section{Statistical analysis}

The variables involved in the analysis are semiquantitative, more precisely they are ordered polytomous categorical values. This means that, if we consider, for example, two values for the percentage of positive cells, say 1 and 2 , these values represent two sets of percentages, less than $10 \%$ and between 10 and $50 \%$. Therefore, the difference between values 1 and 2 cannot be evaluated simply on a linear scale by saying, for instance, that it is 1 . In order to estimate the relationship between scores (percentage of positive cells and intensity) and all other variables, it is more appropriate to use the proportional odds model..$^{21}$ The P-values are obtained with the use of the proportional odds model. Essentially this is a generalization of the regression model suitable for polytomous data. For a given score variable, different regression models can be estimated according to the chosen explanatory variables. We come up with the best model according to the Deviance Criteria. ${ }^{21}$ The P-values, in the Results section, illustrate the significance levels of the regression coefficients that relate the score to the specified variable. The pre-selected significance is $5 \%$. Only for the sake of comparison did we report t-tests using Welch correction, to assess the significance of the relation between a score variable and the group of pigmented lesions. Such analyses were appropriate if the collected score variables (and even their product) were interpretable under a linear scale. The data are presented as mean \pm SEM.

\section{Results}

\section{Clinical-pathological features of melanocytic lesions}

Clinical features of melanocytic lesions, recruited in our study, are presented in Table 1. The 5 blue nevi were from 5 subjects (4 males and 1 female) ranging from 14 to 77 years-old (mean age 45.8). Histologically, they were characterized by the presence of elongated melanocytes with thin, pigmented cytoplasmatic dendrites scattered between undisturbed collagen fibers and a variable number of melanophages. The 18 melanomas included 1 in situ melanoma from a 75 years-old female, 3 in situ melanoma from 3 females ranging from 46 to 76 years-old (mean age 59), 14 superficial spreading melanomas from 14 subjects (6 males and 8 females) ranging from 25 to 78 years-old (mean age 42.8) (Table 2). Histologically, they were characterized by asymmetric proliferations of atypical melanocytes associated with occasional pagetoid spread, mitotic activity and inflammatory reaction. Primary cutaneous melanomas were invasive with Clark's levels ranging from II to

Table 1. Clinical data.

\begin{tabular}{|c|c|c|c|c|c|}
\hline & $\begin{array}{l}\text { No. } \\
(\mathrm{M}: \mathrm{F})\end{array}$ & $\begin{array}{c}\text { Sex } \\
\text { range } \\
\text { (years) }\end{array}$ & $\begin{array}{c}\text { Age } \\
\text { age } \\
\text { (years) }\end{array}$ & Mean & Anatomical site \\
\hline BluNevi & 5 & $4: 1$ & $14-77$ & 45.8 & Foot, arm, scalp(3) \\
\hline Acral melanoma & 1 & $0: 1$ & - & - & Foot \\
\hline Melanoma in situ & 3 & $3: 0$ & $46-76$ & 59 & Back, thorax, foot \\
\hline $\begin{array}{l}\text { Supeficial spreading } \\
\text { melanoma }\end{array}$ & 14 & $6: 8$ & 25-78 & 42.8 & $\begin{array}{l}\text { arm, back (6), thigh, } \\
\text { leg(3), breast, thorax, abdomen }\end{array}$ \\
\hline Metastasis & 3 & $3: 0$ & $59-77$ & 69.6 & Wrist, abdomen, lynphonode \\
\hline Dermal nevi & 5 & $2: 3$ & $19-30$ & 26.4 & Vulva, back, abdomen, scalp, neck \\
\hline Junctional nevi & 3 & $0: 3$ & $33-34$ & 33.3 & Back, leg, foot \\
\hline Compound nevi & 15 & $7: 8$ & $21-60$ & 32.6 & $\begin{array}{l}\text { back(8), thorax, abdomen(2), leg, } \\
\text { pube, shoulder, temple, }\end{array}$ \\
\hline Spitz nevi & 11 & $3: 8$ & $3-50$ & 20,2 & $\begin{array}{l}\operatorname{arm}(3), \operatorname{leg}(2) \text {, hand(2), shoulder, } \\
\text { high, } \operatorname{back}(2)\end{array}$ \\
\hline
\end{tabular}

Table 2. Characteristics of eighteen primary cutaneous melanomas.

\begin{tabular}{|c|c|c|c|c|c|c|}
\hline & Type & Clark & Breslow & Radial phase & Vertical phase & Site \\
\hline 1 & acral & II & 1.2 & + & & Foot \\
\hline 2 & SSM & IV & 1.1 & & + & Back \\
\hline 3 & SSM & II & 0.5 & + & & Abdomen \\
\hline 4 & SSM & IV & 1.6 & & + & Arm \\
\hline 5 & in situ & I & l & 1 & 1 & Back \\
\hline 6 & SSM & II & 0.6 & + & & Leg \\
\hline 7 & SSM & IV & 0.8 & & + & Back \\
\hline 8 & SSM & II & 0.2 & + & & Back \\
\hline 9 & SSM & IV & 1.0 & & + & Thigh \\
\hline 10 & in situ & I & 1 & I & I & Thorax \\
\hline 11 & SSM & IV & 1.0 & & + & Leg \\
\hline 12 & SSM & II & 0.5 & & + & Breast \\
\hline 13 & in situ & I & / & 1 & I & Foot \\
\hline 14 & SSM & II & 0.2 & + & & Leg \\
\hline 15 & SSM & IV & 0.7 & & + & Back \\
\hline 16 & SSM & II & 0.2 & + & & Back \\
\hline 17 & SSM & II & 0.3 & + & & Back \\
\hline 18 & SSM & IV & 2.8 & & + & Thorax \\
\hline
\end{tabular}

SSM, superficial spreading melanoma. 
IV, and Breslow depths ranging from 0.5 up to $2.8 \mathrm{~mm}$ (Table 2). The 3 metastasis were from 3 male subjects, ranging from 59 to 77 yearsold (mean age 69.6). The 23 benign nevi include 3 junctional types from 3 females ranging from 33 to 34 years-old; 5 dermal types from 5 subjects ( 2 males and 3 females) ranging from 19 to 30 years-old (mean age 26.4), 15 compound types from 15 subjects ( 7 males and 8 females) ranging from 21 to 60 years-old (mean age 32.6). Histologically, junctional nevi were characterized by small melanocytes without cytological atypia, organized both in regular aggregates at basis of rete ridges or in lentiginous fashion at dermo-epidermal junction; intradermal nevi were characterized by banal melanocytes organized in aggregates with regular maturation. The 11 Spitz nevi included: 5 junctional types and 6 compound types from 11 subjects ( 3 males and 8 females) ranging from 3 to 50 years old (mean age 20.2). Histologically they were characterized by spindle and epithelioid melanocytes arranged in fascicles or nests with clefting and occasional central spread of melanocytes. Patients with benign melanocytic lesions were younger $(29.6 \pm 2.6)$ than patients with melanoma (47.8 \pm 3.8$)$ and patients with metastatic melanoma $(69.7 \pm 5.4)$. The mean Breslow thickness for melanomas was $0.85 \pm 0.18$ and it has never entered into the statistical analysis (Table 2).

\section{C-Kit expression by immunohisto- chemistry}

Available data of the c-Kit immunohistochemical staining are presented in Tables 3 and 4 . Table 3 summarizes the values of $\mathrm{c}$-Kit intensity staining and Table 4 summarizes the values of percentage of $\mathrm{c}$-Kit positive nevus cells. All 5 blue nevi showed slight cytoplasmatic-membranous positivity of fusate nevus cells with percentage of c-Kit stained cell $<5 \%$, without difference of c-Kit immunohistochemical expression between the top and bottom of lesions. As for the 18 cases of melanoma, the 3 cases of melanoma in situ, one case showed slight (1+) cytoplasmatic positivity with c-Kit stained cell percentage $<5 \%$, the second case showed moderate membranous positivity $(2+)$ with c-Kit stained cell percentage 51-95 \% and the third case (acral type) showed strong $(3+)$ positivity with both membranous and cytoplas- matic pattern, with percentage of c-Kit stained cell $>95 \%$.

The acral melanoma showed strong cytoplasmatic positivity $(3+)$, with percentage of cKit stained cell $>95 \%$ in the junctional component; c-Kit expression in dermal component was moderate $(2+)$ cytoplasmatic, with c-Kit stained cell percentage $51-95 \%$, without substantial difference between the top and the bottom of lesions. The 14 cases of superficial spreading melanoma, showed slight cytoplasmatic positivity in the junctional component $(1+)$ in two cases; moderate intensity $(2+)$ in 7 cases ( 5 cytoplasmatic, 2 both cytoplasmatic and membranous); strong positivity (3+) in 6 cases (4 expressed both cytoplasmatic and membranous pattern and 2 only cytoplasmatic), with percentage of c-Kit stained cell $>5 \%$ in one case, between $5-50 \%$ in 5 cases, between $51-95 \%$ in 3 cases and $>95 \%$ in 5 cases. The intensity of c-Kit stained dermal cell was slight $(1+)$ in 5 cases ( 5 cytoplasmatic); moderate intensity (2+) in 4 cases ( 4 cytoplasmatic and 2 with cytoplasmatic and membranous pattern); strong intensity $(3+)$ in only one case (both cytoplasmatic and membranous pattern); with percentage of $\mathrm{c}$-Kit

Table 3. Immunohistochemical data.

\begin{tabular}{|c|c|c|c|c|c|c|c|c|c|}
\hline \multirow{3}{*}{\multicolumn{2}{|c|}{ n. }} & \multicolumn{8}{|c|}{ Fnidermis Intensity c-Kit staining in tumors cells } \\
\hline & & & Epide & mis & & & De & mis & \\
\hline & & $\begin{array}{c}\text { Negative } \\
0\end{array}$ & $\begin{array}{c}\text { Weak } \\
1\end{array}$ & $\frac{\text { Moderate }}{2}$ & $\begin{array}{c}\text { Strong } \\
3\end{array}$ & $\begin{array}{c}\text { Negative } \\
0\end{array}$ & $\begin{array}{c}\text { Weak } \\
1\end{array}$ & $\begin{array}{c}\text { Moderate } \\
2\end{array}$ & $\begin{array}{c}\text { Strong } \\
3\end{array}$ \\
\hline BluNevi & 5 & 0 & 0 & 0 & 0 & - & 5 & - & - \\
\hline Acral melanoma & 1 & 0 & 0 & 0 & & 0 & 0 & 1 & 0 \\
\hline Melanoma in situ & 3 & 0 & 1 & 1 & 1 & 0 & 0 & 0 & 0 \\
\hline Supeficial spreading melanoma & 14 & 0 & 2 & 7 & 5 & 4 & 5 & 4 & 1 \\
\hline Metastasis & 3 & - & - & - & - & 3 & 0 & 0 & 0 \\
\hline Dermal nevi & 5 & 0 & 0 & 0 & 0 & 1 & 2 & 1 & 1 \\
\hline Junctional nevi & 3 & 0 & 0 & 0 & 3 & - & - & - & - \\
\hline Compound nevi & 15 & 0 & 2 & 10 & 3 & 4 & 8 & 2 & 1 \\
\hline Spitz nevi & 11 & 0 & 10 & 1 & 0 & 3 & 3 & 0 & 0 \\
\hline
\end{tabular}

Table 4. Immunohistochemical data.

\begin{tabular}{|c|c|c|c|c|c|c|c|c|c|c|c|}
\hline \multirow{3}{*}{\multicolumn{2}{|c|}{ n }} & \multicolumn{10}{|c|}{ Percentage of tumors cells expressing $\mathbf{c} \_$Kit } \\
\hline & & & & idermis & & & & & Dermis & & \\
\hline & & $\begin{array}{c}\text { Negative } \\
0\end{array}$ & $\begin{array}{c}<5 \% \\
1\end{array}$ & $\begin{array}{c}5-50 \% \\
2\end{array}$ & $\begin{array}{c}51-95 \% \\
\mathbf{3}\end{array}$ & $>95 \%$ & $\begin{array}{c}\text { Negative } \\
0\end{array}$ & $\begin{array}{c}<5 \% \\
1\end{array}$ & $\begin{array}{c}5-50 \% \\
2\end{array}$ & $\begin{array}{c}51-95 \% \\
3\end{array}$ & $>95 \%$ \\
\hline BluNevi & 5 & - & - & - & - & - & 0 & 5 & 0 & 0 & 0 \\
\hline Acral melanoma & 1 & 0 & 0 & 0 & 0 & 1 & 0 & 0 & 0 & 1 & 0 \\
\hline Melanoma in situ & 3 & 0 & 1 & 0 & 1 & 1 & - & - & - & - & - \\
\hline Supeficial spreading melanoma & 14 & 0 & 1 & 5 & 3 & 5 & 3 & 3 & 4 & 4 & 0 \\
\hline Metastasis & 3 & - & - & - & - & - & 3 & 0 & 0 & 0 & 0 \\
\hline Dermal nevi & 5 & - & - & - & - & - & 1 & 2 & 1 & 1 & 0 \\
\hline Junctional nevi & 3 & 0 & 0 & 1 & 1 & 1 & - & - & - & - & - \\
\hline Compound nevi & 15 & 0 & 0 & 6 & 8 & 1 & 4 & 3 & 6 & 2 & - \\
\hline Spitz nevi & 11 & 0 & 3 & 4 & 4 & 0 & 3 & 2 & 1 & 0 & 0 \\
\hline
\end{tabular}


stained dermal cell $<5 \%$ in 3 cases, between 5 $50 \%$ in 3 cases and $51-95 \%$ in 4 cases. The topbottom evaluation showed seven cases with diffuse positivity without differences in the lesions; three cases showed evident immunoreactivity on the top with gradual decrease to the bottom of lesions. C-kit immunoreactivity was negative in 3 cases of metastatic melanoma. The 3 cases of junctional nevus showed strong c-Kit positivity (3+) (2 membranous, 1 cytoplasmatic) with c-Kit stained cell percentage equal to $5-50 \%$ in one case, $51-95 \%$ in another case and $>95 \%$ in the last one. The 15 primary compound nevus, showed slight epidermic membranous, positivity (1+) in 2 cases, moderate intensity (2+) in 10 cases ( 5 membranous and 5 cytoplasmatic) and strong membranous positivity $(3+)$ in three cases. The percentage of c-Kit stained cell (Table 4) in the epidermis were between 5 $50 \%$ in 6 cases, between $51-95 \%$ in 8 cases and $>95 \%$ in one case. The c-Kit immunoreactivity in the dermic component (Table 3) was slight $(1+)$ in 8 cases (cytoplasmatic), moderate positivity $(2+)$ in two cases (membranous), strong $(3+)$ in one cases (cytoplasmatic), absent in four cases. The percentage c-Kit stained cell in the dermic component (Table 4) was $<5 \%$ in three cases and between $5-50 \%$ in six cases; $51-95 \%$ in two cases, absent in four cases. The top-bottom evaluation showed in 11 cases evident c-Kit positivity in the top with gradual reduction to bottom of lesions whereas in the remaining four cases c-Kit immunoreactivity was homogeneous and diffused to all areas of lesions. In the 5 intradermal nevi, cKit immunoreactivity in the dermic component (Table 3) was slight (1+) in two cases (citoplasmatic and membranous in one case, only citoplasmatic in the other one), moderate (2+) in one case (citoplasmatic and membranous), strong $(3+)$ in one case (membranous), absent in one case. The percentage of $c$-Kit stained cell was $<5 \%$ in two cases and between $5-50 \%$ in one case; $51-95 \%$ in one case, absent in the last case. The top-bottom evaluation was not performed for the absence of the epidermic component. As for the 11 cases of Spitz nevus (5 junctional and 6 compound), the junctional Spitz nevi showed slight positivity (1+) in 4 cases and moderate positivity $(2+)$ in one case; the c-Kit stained cell percentage was between $5-50 \%$ in 3 cases, and $51-95 \%$ in the two remaining cases. All 6 compound Spitz nevi showed slight epidermic positivity (2 membranous and 4 cytoplasmatic), the percentage of c-Kit stained cell was $<5 \%$ in 3 cases, $5-50 \%$ in one case, $51-95 \%$ in two cases. The dermic immunoreactivity for c-Kit was slight (1+) in three cases (cytoplasmatic) with c-Kit stained cell percentage $<5 \%$ in two cases and between $5-50 \%$ in one case, absent in the remaining three cases. The top-bottom evalua- tion in the six compound Spits nevi showed evident c-Kit positivity on top with a gradual decrease to bottom of the lesions in all cases. The vast majority of nevi and melanomas examined in this study were positive for c-Kit, with minimal differences, at microscopic observation, between benign and malignant lesions and with a decrease of c-Kit expression from top to bottom of the lesions. C-Kit was equally expressed in the junctional component of any melanocytic lesions both benign and malignant (Figures 1 and 2). Differences were found in c-Kit immunoreactivity between the intradermal component of benign and malignant melanocytic lesions. In particular, in superficial spreading melanoma with initial dermal invasion, radial growth phase, immunostaning for c-Kit showed higher grades of intensity and a higher percentage of positive melanocytic cells (Figure 3; Table 3 and 4 ). On the contrary in compound nevi, immunostaning was stronger in the junctional component, with a progressive decrease from the top to bottom of the lesion (Figure 4). C-kit staining of the intraepidermal nevus cells demonstrated a cytoplasmic pattern admixed with a membranous pattern. According to the proportional odds model, there was a significant association between the intensity of c-Kit staining in intraepidermal nevus cells and the increasing age of the patient $(\mathrm{P}=0.007)$ (Table 5). Also the percentage of c-Kit-positive intraepidermal nevus cells resulted positively considering the patient's age increasing $(\mathrm{P}=0.014)$ (Table 5); in one case, we observed that the intensity and percentage of positive intraepidermal nevus cell was related to the diameter of the lesion. Intensity of c-Kit expression in dermal melanocytes was significantly higher in the melanoma group compared to the benign lesion group $(\mathrm{P}=0.015)$, as well as the percentage of $c$-Kit-positive dermal
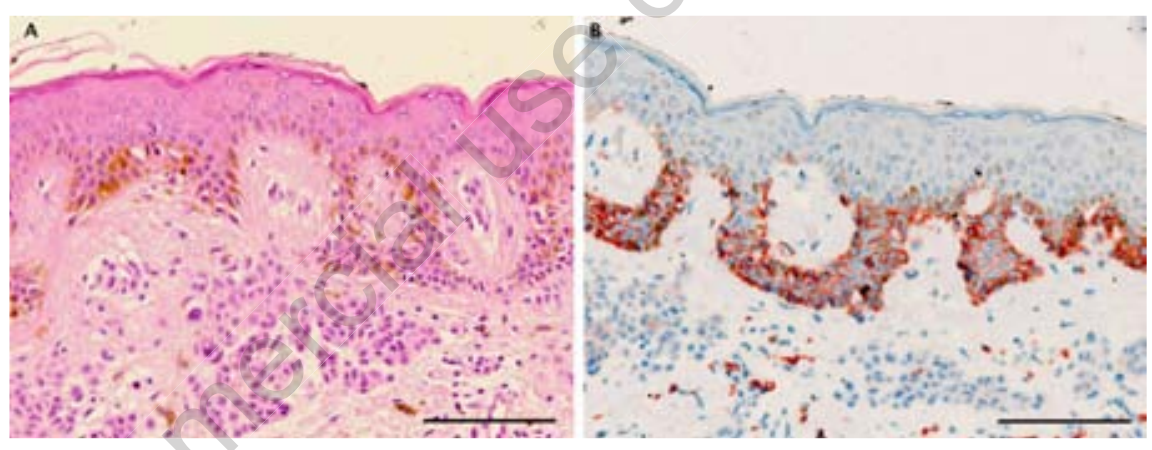

Figure 1. Representative staining results in a case of compound nevus. A) H\&E staining showing a proliferation of junctional and dermal melanocytes with symmetrical pattern and no evidence of cytological dysplasia; B) C-Kit immunohistochemistry showing strong (membranous and cytoplasmatic) expression in the junctional component of compound nevus and weak expression in the dermal component with gradual decrease to the bottom of the lesion. In the reticular dermis frequent c-Kit positive mastcell. Scale bars: $100 \mu \mathrm{m}$.

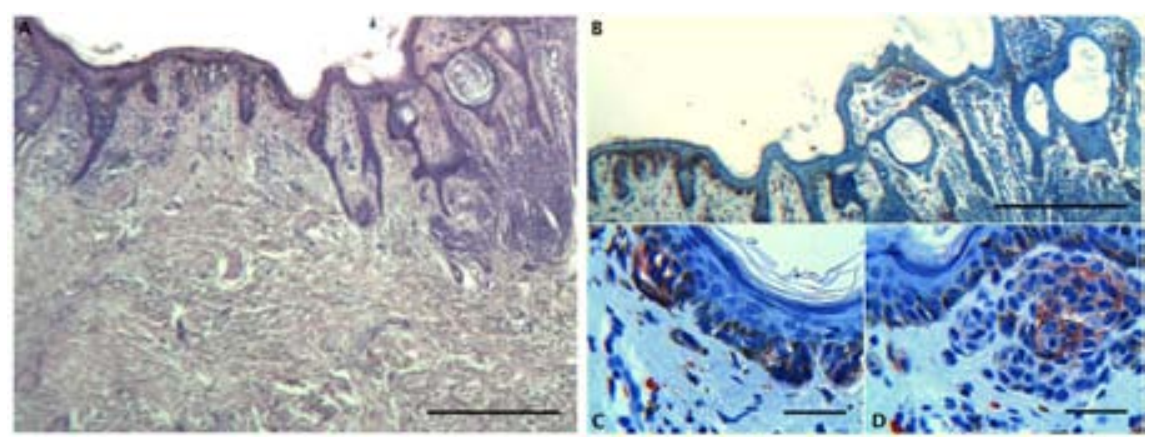

Figure 2. Representative staining results in an interesting case of superficial spreading melanoma on a compound nevus. A) H-E stain showing an in situ superficial spreading melanoma (left) and a compound nevus with a symmetrical pattern and no evidence of cytological dysplasia; B) Prominent CD 117 immunohistochemical staining only at dermoepidermal junction and focal positivity of bottom in the dermal component of compound nevus; C) CD 117 immunohistochemical staining only at dermoepidermal junction of in situ superficial spreading melanoma; D) CD 117 immunohistochemical staining focal positivity at the bottom of the dermal component of compound nevus. A,B, scale bars $200 \mu \mathrm{m}$; C,D, scale bars: $20 \mu \mathrm{m}$. 
melanoma cells $(\mathrm{P}=0.008) \quad$ (Table 5). Interestingly, dermal staining of metastatic melanoma was negative (Figure 5). These final models (represented in Table 5) were obtained after considering age, type, sex and dimension of lesions in order to account for possible confounders. For the sake of comparison, in Table 6 we report the analysis using product staining and t-test with Welch correction as performed by Zhu et al. ${ }^{22}$ For instance, association between expression in dermal melanocytes in the melanoma group compared to benign lesion has a P-value of 0.032 , which is higher than 0.015 (Table 5 and 6). Finally, we also reported no association between epidermal melanocytes in the melanoma group compared to benign lesions with a P-value much higher than 0.057 (either in intensity or percentage).

\section{Discussion}

Benign melanocytic nevi may have occasional cosmetic significance but, for the most part, they are important only in relation to melanoma. Nevi are the most important simulants of melanoma, both clinically and histologically, and can usually be reliably distinguished from melanoma using published criteria. Some benign lesions are characterized by a greater degree of atypia and may be more difficult to diagnose. ${ }^{19}$ Malignant melanoma remains the most contentious of all diagnoses in dermatophatology. While classic histologic criteria have been extensively described over the past four/five decades, interpretation of these criteria remains difficult. ${ }^{23,24}$ Currently, separation of melanomas from nevi is based primarily on light microscopic interpretation of hematoxylin and eosin-stained sections, with limited assistance from immunohistology. The heterogeneous histological features of melanoma may often overlap with melanocytic nevi. For this reason, pathologists have looked to immunohistochemistry to assist with difficult cases. In this challenging diagnostic scenario, many studies have been performed to identify molecular markers that might distinguish benign lesions from malignant melanocytic ones and also the various progression stages in primary malignant melanoma of the skin. ${ }^{25,26} \mathrm{C}$-Kit immunoreactivity has been proposed as a useful tool in the differential diagnosis between deep soft tissue or visceral lesions with melanocytic differentiation; positive staining for c-Kit could exclude the diagnosis of clear cell sarcoma, but it is compatible with the diagnosis of metastatic melanoma. ${ }^{27}$ Kashani-Sabet et al. run some transcriptome analyses that show the differential expression of several genes in melanoma progression. ${ }^{28}$
Table 5. Results with the proportional odds model (Coefficient \pm Standard Error, Pvalue). The first column indicates the specific model in terms of Dependent Variable/Explanatory Variable. Such models have been chosen according to the Deviance Criteria.

Coefficient \pm Standard Brror, P-value of explanatory variables
\[ \begin{array}{c}\text { Age* } \\ \text { Pigmented lesions** }\end{array} \]

$\begin{array}{ll}\text { Epi.Int I Age } & -0.05 \pm 0.02, \mathrm{P}=0.007 \\ \text { Epi.Perc I Age } & -0.04 \pm 0.02, \mathrm{P}=0.014\end{array}$

\begin{tabular}{ll}
\hline Der.Int I Pigmented lesions & $-1.82 \pm 0.73, \mathrm{P}=0.015$ \\
Der.Perc I Pigmented lesions & $-1.89 \pm 0.70, \mathrm{P}=0.008$ \\
\hline
\end{tabular}

${ }^{*}$ Negative coefficients indicate increase with respect to age;**negative coefficients indicate increase in malignant vs. benign lesions.Epi.Int, epidermal melanocytes intensity of c-Kit stain; Epi.Per., epidermal melanocytes percentage of c-Kit stain; Der.Int., dermal melanocytes intensity of c-Kit stain; Der.Perc., dermal melanocytes percentage of c-Kit stain.

Table 6. Results of CD117 immunohistochemical product staining (mean \pm SEM, Pvalue); the P-value refers to the significance of the difference between benign and malignant pigmented lesions for column benign; malignant and metastatic for column malignant; metastatic and benign for column metastatic. Such significance values are calculated with the usual $t$-test.

\begin{tabular}{lccc} 
& $\begin{array}{c}\text { Benign } \\
\text { nevus }\end{array}$ & $\begin{array}{c}\text { Primary malignant } \\
\text { melanoma }\end{array}$ & $\begin{array}{c}\text { Metastatic } \\
\text { melanoma }\end{array}$ \\
Number of cases & 39 & 18 & 3 \\
Epidermal melanocytes & $4.7 \pm 0.5, \mathrm{P}=0.057$ & $7.0 \pm 1.0$, n.a. & n.a., n.a. \\
\hline Dermal melanocytes & $1.8 \pm 0.4, \mathrm{P}=0.032$ & $4.0 \pm 0.8, \mathrm{P}<0.001$ & $0 \pm 0, \mathrm{P}<0.001$ \\
\hline
\end{tabular}

n.a., not available.
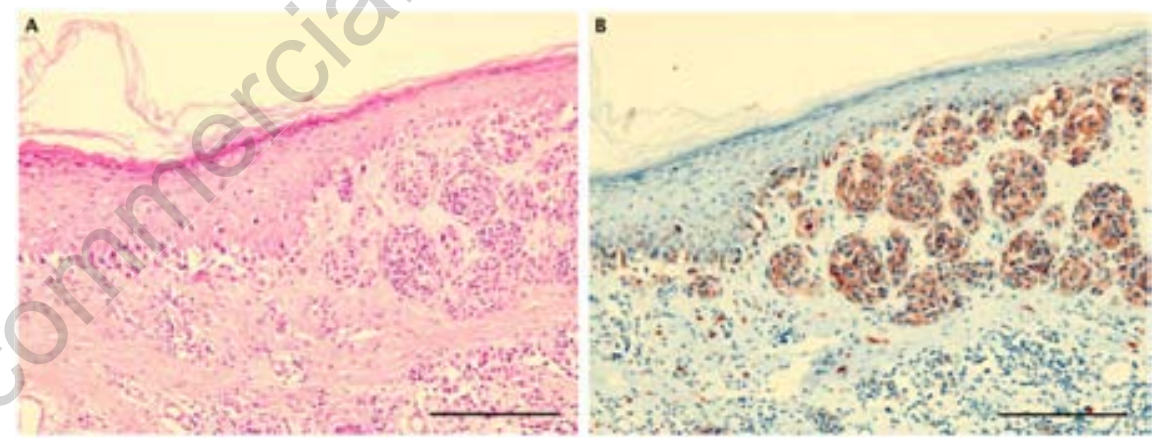

Figure 3. Representative staining in a case of superficial spreading melanoma (vertical growth phase). A) H\&E staining showing a melanocytic proliferation with architectural disorder; B) prominent c-Kit immunostaining both at the junctional and dermic component. Scale bars: $200 \mu \mathrm{m}$.

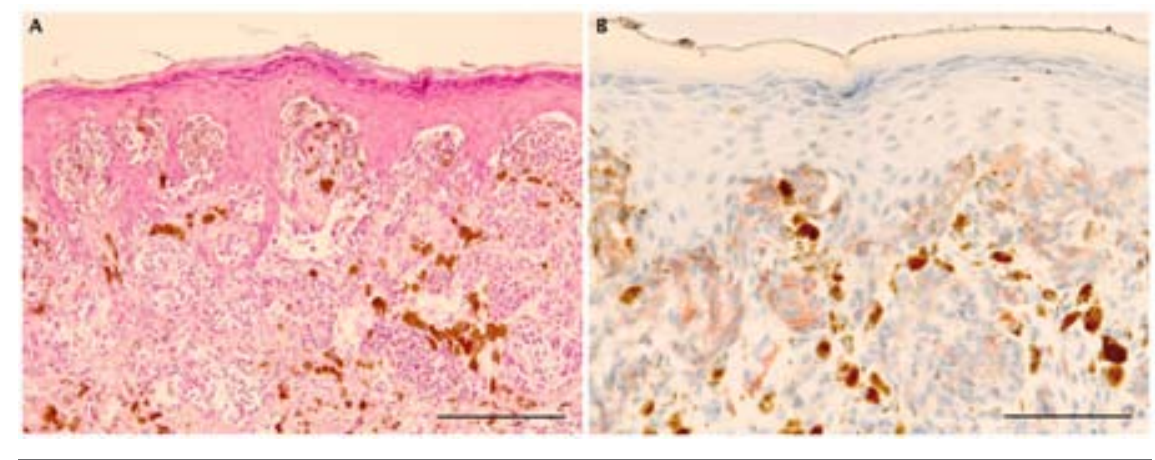

Figure 4. Representative staining in a case of Spitz nevus. A) H\&E staining showing a proliferation of spindle and epitelioid melanocytes with symmetrical pattern and no evidence of cytological dysplasia; B) prominent c-Kit immunohistochemical staining at dermoepidermal junction and progressive decrease positivity in the dermis. Scale bars: $200 \mu \mathrm{m}$. 
They also performed a multi-marker diagnostic assay using 5 markers (ARPC2, FN1, RGS1, SPP1 and WNT2), which are over-expressed in melanoma cells. Gould Rothberg et al. proposed that the ratio of nuclear to non-nuclear HMB45 immunofluorescence staining may be useful in the diagnosis of melanocytic lesions. $^{29}$ Recent data has shown also that PAX3 is commonly expressed in primary melanoma samples (21/58), but significantly less frequently in benign pigmented lesions (9/75)..$^{30}$ Additionally, IMP-3 (insulin-like growth factor-II messenger RNA-binding protein-3) may have diagnostic utility in distinguish melanoma from benign nevi, displastic nevi and Spitz nevi. ${ }^{31}$ Zhu et al. proposed that CD117 is unlikely to be a useful diagnostic tool to differentiate Spitz nevus from malignant melanoma but may be useful to differentiate metastatic melanoma from primary melanoma in patients who have a history of melanoma and who presented with new dermal lesions. ${ }^{22}$ Increased Wilms' tumor 1 protein (WT1) expression has been proposed as a marker of melanoma cells. However, as a single immunostaining marker, WT1 is not sufficient to distinguish melanoma from benign melanocytic nevi. ${ }^{32}$ Hillard et al. retained that the staining pattern for p16 in desmoplastic melanomas and Spitz nevi, in conjunction with the histopathologic features, S100 staining, Ki67 proliferation index and clinical scenario may aid in the difficult differential diagnosis between these two entities. ${ }^{33}$ Ribè and Scot McNutt assessed an immunohistochemical test for S100A6 protein to differentiate Spitz nevi from melanoma and melanocytic nevi: ${ }^{34}$ this marker can be used when the distinction is very difficult or controversial in routine studies, especially when there is a junctional component. CD117 is an indicator of malignant proliferative process and reported that while $59 \%$ of benign melanocytic nevi express c-Kit, $100 \%$ of displastic nevi and $96 \%$ of primary melanoma express c-Kit. ${ }^{8}$ In our study, we observed that c-Kit, in the junctional component of benign and malignant lesions, is constantly expressed, with minimal differences between intensity and percentage, while in the dermal component of both benign nevi and melanomas there is a decrease in expression of c-Kit. In metastatic melanoma with only dermal component, c-Kit expression was absent or minimally present as well as been reported by Zhu et al. and Guerriere et al. ${ }^{22,25}$ Besides a decrease of c-Kit expression in the intradermal component of pigmented lesions, our statistical data showed higher values of the intensity and of the percentage c-Kit positive cells in melanomas. Our study suggests that c-Kit is not a specific marker discriminator between junctional component of benign melanocytic nevi and superficial spreading
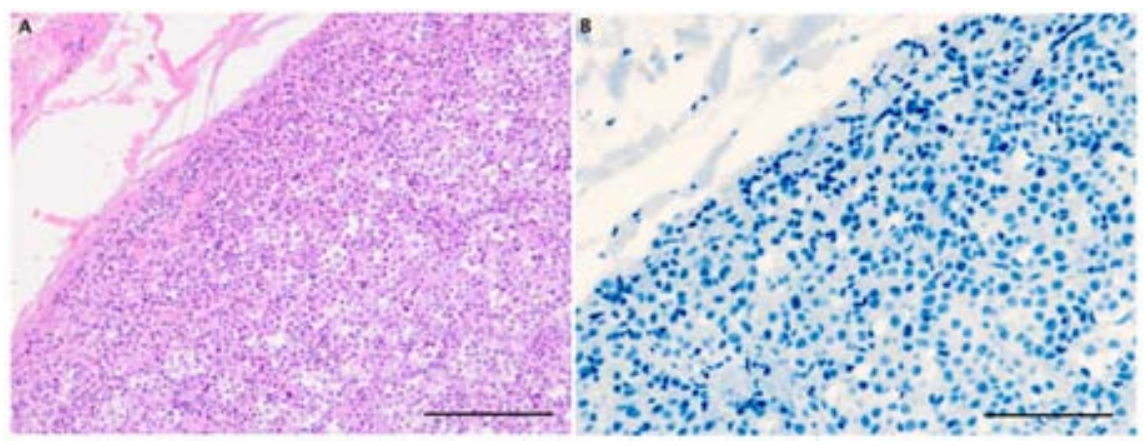

Figure 5. Representative staining results in a case of metastatic melanoma. A) H\&E staining; B) negative staining for c-Kit. Scale bars: $200 \mu \mathrm{m}$.

melanoma. In fact the intensity and percentage of c-Kit in intraepidermal melanocytes was not correlated with the type of pigmented lesions (benign melanocytic nevi and superficial spreading melanoma). In fact also in junctional nevi, compound nevi, and Spitz nevi, the intraepidermic melanocytes showed intense and diffuse c-Kit positivity as well as the proliferant melanocytes of melanoma in situ and of superficial spreading melanoma. At microscopic analysis we observed, in the intradermic component of pigmented lesions, that intensity and percentage of c-Kit positive cells was higher in melanomas than in nevi, this is moreover proved by statistical analysis. It was speculated that in the model of tumor progression in malignant melanoma (atypical intraepidermic proliferation followed by a radial growth phase then a vertical growth phase) to acquire proliferative advantage and escape from epidermal boundaries, melanoma cells should lose Kit expression. ${ }^{35}$ This hypothesis was supported by previous observations in which Kit expression in melanoma was strong in the melanoma in situ and in the junctional component of invasive lesions, but was lost once the melanoma became invasive and metastatic. ${ }^{15,25}$ Also our data supported this intriguing hypothesis, in fact our superficial spreading melanomas, in radial phase or in vertical phase, even though with an intensity and percentage of c-Kit positive dermic nevus cells higher than in the benign intradermic and compound nevi, showed an initial decrease of c-Kit expression from the top to the bottom of lesions. Only one case of superficial spreading melanoma, in the vertical growth phase, showed diffuse and intense cKit positivity (Figure 3). Also the real loss of ckit expression in our three metastasis corroborate this hypothesis. Marked intensity in junctional components and gradual decrease of c-Kit expression in dermal component is observed both in intradermal and compound nevi, up to range a real loss of c-Kit expression in the bottom of lesions, as was observed in melanomas. We supposed that, in benign nevi, this junctional marked c-Kit intensity with gradual decrease in dermal component, could be explained as result of a motogen effect..$^{35} \mathrm{C}$ Kit expression could indicate melanocytes during their migration phase. Therefore, the migratory direction in melanocytic lesions is from dermis to epidermis. ${ }^{35}$ We additionally observed a real c-Kit over-expression in two cases of acral melanoma, even if Kit mutation is not tested. This observation is not in contrast to literature data. Curtin et al. found that more than a third of the acral, mucosal and sun induced melanomas without detectable Kit mutation or copy number increase, showed over-expression of Kit by immunohistochemistry led to hypothesize that other mechanisms than gene mutation or amplification could explain the observed Kit over-expression. ${ }^{36}$ In our study, variables like intensity and percentage increased only if correlated with the patient's age. However, scores of intensity and percentage of c-Kit, only in dermal melanocytes resulted statistically different between benign and malignant lesions: those variables were more expressed in melanoma cells than in nevus cells. In summary on the basis of our data, c-Kit should not be considered as an indicator of malignant proliferative process but may be considered as a result of the motogenic effect of proliferating melanocytes. It could further be a useful marker to differentiate primary melanoma from compound nevi while seeming to be not entirely useful to differentiate melanocytic junctional nevi from melanoma in situ or superficial spreading melanoma in radial phase.

\section{References}

1. Matsui Y, Zsebo KM, Hogan BL. Embryonic expression of a haematopoietic growth factor encoded by the SI locus and the ligand for c-kit. Nature 1990;347:667-9. 
2. Sette C, Dolci S, Geremia R, Rossi P. The role of stem cell factor and of alternative ckit gene products in the establishment, maintenance and function of germ cells. Int J Dev Biol 2000;44:599-608.

3. Rossi P, Sette C, Dolci S, Geremia R. Role of c-kit in Mammalian Spermatogenesis. J Endocrinol Invest 2000;23:609-615.

4. Yarden Y, Kuang WJ, Yang-Feng T, Coussens L, Munemitsu S, Dull TJ, et al. Human proto-oncogene c-kit: a new cell surface receptor tyrosine kinase for an unidentified ligand. EMBO 1987;6:334151.

5. Qiu F, Ray P, Brown K, Baker PE, Jhanwar $\mathrm{S}$, Ruddle FH, et al. Primary structure of $\mathrm{c}$ kit: relationship with the CSF-1/PDGF receptor kinase family/oncogenic activation of v-kit involves the deletion of extracellular domain and $\mathrm{C}$ terminus. EMBO 1988;7:1003-11.

6. Linnekin D. Early signalling pathways activated by c-Kit in hematopoietic cells. Int $\mathrm{J}$ Biochem Cell Biol 1999;31:1053-74.

7 WuY, LiY, Saleem S, Yee SP, Hardikar AA, Wang R. C-Kit and stem cell factor regulate PANC-1 cell differentiation into insulinand glucagons- producing cells. Modern Pathol 2010;90: 1373-84.

8. Loveland KL, Schlatt S. Stem cell factor and c-kit in the mammalian testis: lessons originating from Mother Nature's gene knockouts. J Endocrinol 1997;153:337-44.

9. Lammie A, Drobnjak M, Gerald W, Saad A, Cote R, Cordon-Cardo C. et al. Expression of $\mathrm{c}$-Kit and Kit ligand proteins in normal human tissues. J Histochem Cytochem 1994;42:1417-25.

10. Penner CR, Folpe AL, Budnick SD. C-Kit expression distinguishes salivary gland adenoid cystic carcinoma from polymorphous low-grade adenocarcinoma. Mod Pathol 2002;15:687-91.

11. Funasaka Y, Boulton T, Cobb M, Yarden Y, Fan B, Lyman SD, et al. C-Kit chinase induces a cascade of protein tyrosinase phosphorilaton in normal human melanocytes in response to mast cell growth and stimulates mitogen-activated protein chinase but is down-regulated in melanomas. Mol Biol Cell 1992;3:197-209.

12. Shen SS, Zhang PS, Eton 0, et al. Analysis of protein tyrosine kinase expression in melanocytic lesions by tissue array. J Cutan Pathol 2003;30:539-47.

13 Potti A, Hille RC, Koch M. Immunohistochemical determination of HER$2 /$ neu overexpression in malignant mela- noma reveals no prognostic value, while cKit (CD117) overexpression exhibits potential therapeutic implications. J Carcinog 2003;2:1-7.

14. Lassam N, Bickford S. Loss of c-Kit expression in cultured melanoma cells. Oncogene 1992;7:51-6.

15. Natali PG, Nicotra MR, Vinkler AB, Cavaliere R, Bigotti A, Ulrich A. Progression of human cutaneous melanoma is associate with loss of expression of c-Kit proto-oncogene receptor. Int $\mathrm{J}$ Cancer 1992;52:197-201.

16. Zacut R, Perlis R, Eliyahu S, Yarden Y, Givol D, Lyman SD, et al. KIT ligand (Mast cells growth factor) inhibits the growth of KIT-expressing melanoma lines cells. Oncogene 1993;8:222-39.

17. Stefanou D, Batistatou A, Zioga A, Arkoumani E, Papachristou DJ, Agnantis NJ. Immunohistochemical expression of vascular endothelial growth factor (VEGF) and C-KIT in cutaneous melanocytic lesions. Int J Surg Pathol 2004;12:133-8.

18. Potti A, Moazzam N, Langness E, Sholes K, Tendulkar K, Koch M, et al. Immunohistochemical determination of HER2/neu, c-Kit (CD117), and vascular endothelial growth factor (VEGF) overexpression in malignant melanoma. J Cancer Res Clin Oncol 2004;130:80-6.

19. Cerroni L, Barnhill R, Elder D, Gottlieb G, Heenan P, Kutzner H, et al. Melanocytic tumors of uncertain malignant potential. Am J Surg Pathol 2010;34:314-26.

20. Torres-Cabala CA, Wang WL, Trent J, Yang D, Chen S, Galbincea J, et al. Correlation between KIT expression and Kit mutation in melanoma: a study of 173 cases with emphasis on the acral-lentiginous/mucosal type. Modern Patholog 2009;22:1446-56.

21. McCullagh P, Nelder JA. Chapter 5. Models for polytomous data. Generalized Linear Models, 2nd Edition. 1989, Chapman \& Hall, London, UK.

22. Zhu YI, Fitzpatrick JE. Expression of c-kit (CD117) in Spitz nevus and malignant melanoma. J Cutan Pathol 2006;33:33-7.

23. Elder DE. Precursors to melanoma and their mimics: nevi of special site. Modern Pathology 2006:19S4-S20.

24. Bruce R Smaller. Histologycal criteria for diagnosing primary cutaneous malignant melanoma, Mod Pathol 2006;Suppl.2:4-20.

25. Guerriere-Kovach PM, Hunt EL, Patterson JW, Glembocky DJ, English JC 3rd, Wich MR. Primary melanoma of the skin and cutaneous melanomatous metastases: comparative histologic features and immunophenotypes. Am J Clin Pathol 2004;122:70-7.

26. van Kempen LC, van den Oord JJ, van Muijen GN, Weidle UH, Bloemers HP. Swart GW activated leukocyte cell adhesion molecule/CD166, a marker of tumor progression in primary malignant melanoma of the skin. Am J Pathol 2000; 156:769-4.

27. Garcia JJ, Kramer MJ, Mackey ZB, 0'Donnell RJ, Horvai AE. Utility of CD117 immunoreactivity in differentiating metastatic melanoma from clear cell sarcoma. Arch Pathol Lab Med 2006; 130:343-8.

28. Kashani-Sabeta M, Rangel J, Torabian S, Nosrati M, Simko J, Jablons DM, et al. A multi-marker assay to distinguish malignant melanomas from benign nevi. Proc Natl Acad Sci USA 2009;106:6268-72.

29. Rothberg BE, Moeder CB, Kluger $\mathrm{H}$, Halaban R, Elder DE, Murphy GF, et al. Nuclear to non-nuclear Pmel17/gp100 expression (HMB45 staining) as a discriminator between benign and malignant melanocytic lesions. Mod Pathol 2008; 21:1121-29.

30. Plummer RS, Shea CR, Nelson M, Powell SK, Freeman DM, Dan CP, et al. PAX3 expression in primary melanomas and nevi. Mod Pathol 2008;21:525-30.

31. Pryor JG, Bourne PA, Yang Q, Spaulding BO, Scoutt GA, Xu H. IMP-3 is a novel progression marker in malignant melanoma. Mod Pathol 2008;21:431-7.

32. Rosner K, Mehregan DR, Moussai D, Abrams J, Tromp G, Mehregan DA. WT1 marker is not sufficient for distinguishing between melanoma and melanocytic nevi. J Cutan Pathol 2009;36:1077-82.

33. Nicholaus J Hilliard, Dieter Krahl, Klaus Sellheyer. p16 Expression differentiates between desmoplastic Spitz nevus and desmoplastic melanoma. J Cutan Pathol 2009;36:753-9.

34. Ribé A, McNutt NS. S100A6 protein expression is different in dpitz nevi and melanomas. Mod Pathol 2003;16:505-11.

35. Alexeev V, Yoon K. Distinctive Role of the cKit Receptor Tyrosine Kinase Signaling in Mammalian Melanocytes. J Invest Dermatol 2006;126:1102-10.

36. Curtin JA, Busam K, Pinkel D, Bastian BC. Somatic activation of Kit in distinct subtypes of melanoma. J Clin Oncol 2006;24: 4340-46. 